\title{
OBSTETRIC OUTCOME OF PREGNANCIES FOLLOWING ABORTIONS
}

\author{
Chintan Upadhyay ${ }^{1}$, Mahesh Koregol' ${ }^{2}$, Ratna Bulusu ${ }^{3}$, Swati Dubey ${ }^{4}$, Nisha Shah ${ }^{5}$
}

\section{HOW TO CITE THIS ARTICLE:}

Chintan Upadhyay, Mahesh Koregol, Ratna Bulusu, Swati Dubey, Nisha Shah. "Obstetric outcome of pregnancies following abortions". Journal of Evolution of Medical and Dental Sciences 2013; Vol2, Issue 31, August 5; Page: 5755-5758.

OBJECTIVE: To evaluate the Obstetric outcome in Pregnancies with history of one or more abortions. MATERIALS AND METHODS: This is a retrospective study Conducted at Dr. B.R. Ambedkar Medical College, Bangalore. Record review of cases was done from January 2005 to December 2009. Inclusion criteria were pregnancies with history of previous abortions. These cases were compared with a group of controls. RESULTS: There were 412 cases with previous history of abortions. There were 272 (66\%) booked cases while 140 (33.9\%) were unbooked cases. 347 (84.2\%) patients crossed viable period of pregnancy (more than 28 weeks). 56 (13.5\%) patients had repeat abortions. Pregnancies complicated by high risk factors were 177(42.9\%). 176(49.43\%) patients underwent vaginal delivery and 138 (38.7\%) underwent cesarean section. 77 (21.6\%) of Babies were low birth weight while others were above $2.5 \mathrm{~kg}$. There were 46 (12.9\%) preterm babies and 12 (2.9\%) Intrauterine demise of fetuses. These were compared to a group of controls and discussion is carried out. CONCLUSION: Patients with previous history of abortions are at increased risk of adverse maternal and perinatal outcome.

INTRODUCTION: Abortion is a much debated issue, debate about its cause, association and pathophysiological mechanism. Historically, clinicians have grouped all pregnancy losses that occur at gestation prior to theoretical viability under the umbrella of 'abortion'. More recently, researchers have reclassified pregnancy loss as a more complex phenomenon and many scholars have done research on the relationship of abortion and subsequent pregnancy outcome. ${ }^{1}$

Each year 22 million unsafe abortions are estimated to take place worldwide. Nearly all unsafe abortions (98\%) occur in developing countries. The total number of unsafe abortions has increased from about 20 million in 2003 to 22 million in $2008{ }^{2}$

Miscarriage or spontaneous pregnancy loss before 24 completed weeks of gestation is estimated to affect $10-15 \%$ of pregnancies. ${ }^{3}$ While a spontaneous miscarriage is distressing at any time, it is particularly so if it occurs in the first pregnancy. ${ }^{4}$

\section{MATERIALS AND METHODS:}

This is a retrospective study conducted at Dr. B.R. Ambedkar Medical College, Bangalore. Record review of 532 cases was done from January 2005 to December 2009, among which 412 were cases and 120 controls. The cases have previous one, two, three or more abortions. The controls were those, who do not have previous history of any abortion. The baseline data recorded in all patients were maternal age, Period of gestation, Mode of delivery, maternal and fetal outcome. These factors were compared between cases and control group. 
RESULTS: Out of 412 cases 330 (80.09\%) had previous one abortion, 62 (15.04\%) had previous two abortions and 20 (4.8\%) had previous three or more abortions. We found highest numbers of Abortion were 6 in our study.

In our study $33.9 \%$ were unbooked cases compared to control (17.5\%) shown as in Table 1.

Table 1:

\begin{tabular}{|c|c|c|}
\hline & CASES & CONTROLS \\
\hline BOOKED & $272(66 \%)$ & $99(82.5 \%)$ \\
\hline UNBOOKED & $140(33.9 \%)$ & $21(17.5 \%)$ \\
\hline
\end{tabular}

In our study majority of the cases (48.3\%) were from 21 - 25 years of age group.

Period of gestation was compared in table 2 .

Table 2:

\begin{tabular}{|c|c|c|}
\hline POG ( WEEKS) & CASES & CONTROL \\
\hline $28-36$ & $50(12.1 \%)$ & $23(19.1 \%)$ \\
\hline $37-40$ & $284(68.9 \%)$ & $91(75.8 \%)$ \\
\hline$>40$ & $13(3.1 \%)$ & $6(5 \%)$ \\
\hline
\end{tabular}

In our study we found in maternal outcome some of high risk factors like severe anemia, pre eclampsia, oligohydramnios, pre term labour, cesarean section, repeat abortions and IUD. These were higher than controls and some of them were indications for cesarean section in current pregnancy.

Table 3 shows mode of delivery and table 4 shows high risk factors of maternal outcome.

\section{Table 3:}

\begin{tabular}{|c|c|c|}
\hline Mode of delivery & Cases & Control \\
\hline Vaginal & $176(49.4 \%)$ & $78(65 \%)$ \\
\hline LSCS & $138(38.7 \%)$ & $32(26.6 \%)$ \\
\hline
\end{tabular}

Table 4:

\begin{tabular}{|c|c|c|}
\hline Risk factors & Cases & Control \\
\hline Repeat abortions & $56(13.5 \%)$ & - \\
\hline Pre eclampsia & $27(7.5 \%)$ & $2(1.6 \%)$ \\
\hline Oligohydramnios & $26(7.3 \%)$ & $6(5 \%)$ \\
\hline PROM & $35(9.8 \%)$ & $10(8.3 \%)$ \\
\hline Breech & $13(3.6 \%)$ & $1(0.8 \%)$ \\
\hline IUGR & $7(1.9 \%)$ & $2(1.6 \%)$ \\
\hline
\end{tabular}


We found $56(13.5 \%)$ cases out of 412 cases had again land up in abortion, majority of them were unbooked cases and occurred in $6-14$ weeks (92.8\%) of gestations.

In our study pre term birth were $12.9 \%$, IUD were $2.9 \%$ and low birth weight babies were $21.6 \%$ compared to control $5.8 \%, 0.8 \%$ and $20 \%$ respectively as perinatal outcome.

Table 5: shows perinatal outcome

\begin{tabular}{|c|c|c|}
\hline Risk factor & Cases & Control \\
\hline Pre term & $46(12.9 \%)$ & $7(5.8 \%)$ \\
\hline IUD & $12(2.9 \%)$ & $1(0.8 \%)$ \\
\hline Low birth weight $(<2.5 \mathrm{~kg})$ & $77(21.6 \%)$ & $24(20 \%)$ \\
\hline
\end{tabular}

DISCUSSION: In comparison with women with a previous successful pregnancy, our data suggest that women with an initial miscarriage have an increased risk of some obstetric complications. These include pre-eclampsia, threatened miscarriage, nonspecific antepartum hemorrhage, and induced labour, instrumental delivery. They are also more prone to preterm delivery, malpresentation and low birth weight.

Our results show that any pregnancy following an initial miscarriage is associated with a degree of increased obstetric and perinatal risk. This study questions the evidence behind the attribution of risk only to women who have had three or more consequent miscarriages (recurrent miscarriage). At the same time, the magnitude of this risk is likely to be small as women with a history of recurrent miscarriage achieve good pregnancy outcomes with support from an early pregnancy unit.

In one of the study, Kashanian $\mathrm{M}$ et al found that there is risk of repeat abortion (16.5\%), fetal death $(1.5 \%)$ and rate of cesarean section $(28.1 \%)$ were increased in previous miscarriage cases. ${ }^{5}$ in our study we also found same results .

Study done by Jivraj et al in Sept 2000 found that rates of preterm delivery (13\%), perinatal loss $2.5 \%$ and caesarean section (36\%) were significantly high. ${ }^{6}$

In one of the previous study Bhattacharya et al 2008, stated that miscarriage group faced a higher risk of pre eclampsia (4.4\%), threatened abortion $(27.1 \%)$, rate of caesarean section (4.2\%), preterm delivery $(9.2 \%)$ and low birth weight $(8.5 \%)^{7}$. Incidence of high risk factors were also increased in our study as described in above results.

CONCLUSION: Women with an initial miscarriage are at increased risk of some obstetric and perinatal complications in comparison with women who have a successful initial pregnancy. The risks of pre-eclampsia, PROM, oligohydramnios, rate of caesarean section, preterm delivery, repeated miscarriage, low birth weight, operative interference and IUD are higher in women with an initial miscarriage. Therefore, patients with recurrent miscarriage represent of population at high risk of obstetric problems and close surveillance during the antenatal period is required.

\section{REFERENCES:}

1. L. Bricker. Types of pregnancy loss in recurrent miscarriage, Human reproduction volume 17, No.5, pp 1345 - 1350, 2002. 
2. Policy guidance for health system - WHO, $2^{\text {nd }}$ edition, chapter $1 \mathrm{pp}-17$

3. Wilcox AJ, Weinberg CR, O'Connor JF, Baird DD, Schlatterer JP, Canfield RE, et al. Incidence of early loss of pregnancy. N Engl J Med 1988; 319: 189-94.

4. Regan L, Braude PR, Trembath PL. Influence of past reproductive performance on risk of spontaneous abortion. BMJ 1989; 299:541-5. Erratum appears in BMJ 1989;299: 1082

5. Kashanian M, Akbarian A.R, Baradaran H, Shabandoust S.H. Pregnancy Outcome following a Previous Spontaneous Abortion (Miscarriage). Gynecol Obstet Invest 2006; 61:167-170.

6. Obstetric and neonatal outcome in women with a history of recurrent miscarriage: a cohort study. S. Jivraj1, oxford journals, volume 16, issue 1, sept 2000, p 102 - 106.

7. Does miscarriage in an initial pregnancy lead to adverse obstetric and perinatal outcomes in the next continuing pregnancy? S Bhattacharya . Volume 115, issue - 13, page 1623 - 1629 . Dec-2008,

\section{AUTHORS:}

1. Chintan Upadhyay

2. Mahesh Koregol

3. Ratna Bulusu

4. Swati Dubey

5. Nisha Shah

\section{PARTICULARS OF CONTRIBUTORS:}

1. Senior Resident, Department of Obstetrics and Gynecology, GMERS Medical College, Sola, Ahmadabad.

2. Ex Assistant Professor, Department of Obstetrics and Gynecology, Dr. B.R. Ambedkar Medical College, Bangalore.

3. Professor \& HOD, Department of Obstetrics and Gynecology, Dr. B.R. Ambedkar Medical College, Bangalore.
4. Post Graduate Sutdent, Department of Obstetrics and Gynecology, SMIMS, Sikkim

5. Assistant Professor, Department of Pediatrics, U.N Mehta cardiac institute. Ahmadabad.

\section{NAME ADRRESS EMAIL ID OF THE CORRESPONDING AUTHOR:}

Dr. Chintan M Upadhyay.

"Kailas", No. 345, Sector - I, Gandhinagar, Gujarat 382010.

Email-drchintanupadhyay@yahoo.com

Date of Submission: 24/06/2013.

Date of Peer Review: 25/07/2013.

Date of Acceptance: 27/07/2013.

Date of Publishing: 31/07/2013 